\title{
ELEMENTOS PLATÔNICOS PARA UMA TEORIA CRÍTICA DA SOCIEDADE: UMA LEITURA MARCUSEANA DE PLATÃO
}

\author{
Adauto Lopes da Silva Filho ${ }^{1}$ \\ Felipe Bezerra de Castro Oliveira ${ }^{2}$ \\ Jéssyca Aragão de Freitas ${ }^{3}$
}

\begin{abstract}
Resumo:
O presente artigo aborda a filosofia platônica a partir da perspectiva de leitura desenvolvida pelo filósofo alemão Herbert Marcuse (1898-1979) em O homem unidimensional: estudos da ideologia da sociedade industrial avançada (1964). Com base no capítulo Pensamento negativo: a lógica derrotada do protesto, pretendemos examinar os elementos presentes na filosofia platônica que contribuem para a articulação de uma teoria crítica da sociedade, demonstrando como estes elementos apontam para uma mudança social comprometida com uma prática histórica libertadora. Nossa problemática se centra na lógica de dominação característica da sociedade industrial avançada, cujo projeto ofusca os elementos emancipatórios da razão. Daí a necessidade de resgatar, na dialética platônica, elementos comprometidos com a emancipação do homem. Para delinear o plano de nossa proposta, utilizaremos a obra Razão e revolução: Hegel e o advento da teoria social (1941), artigos contidos em Tecnologia, guerra e fascismo (1999) e alguns diálogos platônicos, principalmente o Mênon e a República.
\end{abstract}

Palavras-chave: Teoria crítica da sociedade. Mudança Social. Lógica de dominação. Dialética platônica. Emancipação.

\section{PLATONIC ELEMENTS FOR A CRITICAL THEORY OF SOCIETY: A MARCUSEAN READING OF PLATO}

\begin{abstract}
:
This article discusses Platonic philosophy from the reading perspective developed by the German philosopher Herbert Marcuse (1898-1979) in One-Dimensional Man: studies in the ideology of advanced industrial society (1964). Based on chapter Negative thinking: the defeated logic of protest, we aim to examine the elements present in Platonic Philosophy that contribute to the articulation of a critical theory of society, demonstrating how they point out to a social change committed to a liberating historical practice. Our problematic focuses on the logic of domination which is characteristic of the advanced industrial society, whose project obscures the emancipatory elements of reason. Hence the need to rescue, in the Platonic dialectic, elements committed to the emancipation of man. To outline the plan of our proposal, we will use the work Reason and Revolution: Hegel and the rise of social theory (1941), articles contained in Technology, War and Fascism (1999) and some Platonic dialogues, especially the Meno and Republic.
\end{abstract}

Keywords: Critical theory of society. Social change. Logic of domination. Platonic dialectic. Emancipation.

\section{Introdução}

1 Doutor em Educação, Mestre e Graduado em Filosofia. Professor de Filosofia da Universidade Federal do Ceará. Membro efetivo do Programa de Pós-Graduação em Educação e do Programa de Pós-Graduação em Filosofia da UFC. E-mail: adautoufcfilosofia@gmail.com.

2 Mestrando em filosofia pela Universidade Federal do Ceará, com linha de pesquisa em Ética e Filosofia Política. E-mail: felipe.bezerra3000@bol.com.br.

3 Mestra em filosofia pela Universidade Estadual do Ceará, com linha de pesquisa em Ética Fundamental. Doutoranda em filosofia pela Universidade Federal do Ceará, com linha de pesquisa em Filosofia da Linguagem e do Conhecimento. E-mail: jessycaragao@ hotmail.com. 
Quando se trata da formação intelectual do filósofo alemão Herbert Marcuse, os nomes de Hegel, Marx e Freud logo ecoam como influências fundamentais ${ }^{4}$. Todavia, ainda que de forma mais atenuada, o filósofo grego Platão também exerceu certa contribuição ao pensamento político de Marcuse. Para nos delimitar especificadamente nessa influência, retomaremos aos escritos marcuseanos da década de 40. Foi nesse período que Marcuse, juntamente com Franz Neumann, elaborou um projeto pautado em identificar a "teoria da mudança social" ao longo da história da filosofia ${ }^{5}$. É a partir desse projeto que o filósofo de Frankfurt desenvolve uma leitura da filosofia antiga voltada para a mudança social identificada "com o progresso da vida humana e que deveria ser medido de acordo com as possibilidades existentes da vida humana" (MARCUSE, 1999, p. 140). De início, defendemos que essa proposta de leitura dos clássicos da cultura ocidental permeia a teoria crítica de Marcuse $^{6}$. Nesse sentido, delinearemos algumas considerações que sustentam esta hipótese.

Na obra O homem unidimensional (1964), Marcuse afirma que uma teoria crítica da sociedade "analisa a sociedade à luz de suas capacidades - usadas e não usadas ou abusadas - de melhorar a condição humana" (MARCUSE, 2015, p. 32). Ao assumir esse pressuposto, torna-se inevitável que Marcuse interprete Platão à luz desse projeto de mudança social radical $^{7}$, examinando alguns elementos do corpus platônico que se adéquam à sua teoria crítica social ${ }^{8}$.

Sabendo que $O$ homem unidimensional dispõe de uma análise rigorosa das novas formas de controle e dominação estruturados pela sociedade industrial avançada (KELLNER, 2015, p. 15), o presente artigo propõe um exame da leitura marcuseana de Platão, com o

4 Sobre a influência de Hegel, Marx e Freud no pensamento de Marcuse, $C f$. MERQUIOR, José Guilherme. Arte e sociedade em Marcuse, Adorno e Benjamin: ensaio crítico sobre a escola neo-hegeliana de Frankfurt. São Paulo: É Realizações, 2017. p. 28-37.

5 Esse projeto está presente nos textos Uma história da doutrina da mudança social e Teorias da mudança social. Cf. MARCUSE, Herbert. Tecnologia, guerra e fascismo. Tradução de Maria Cristina Vidal Borba; revisão de tradução de Isabel Maria Loureiro. São Paulo: Fundação Editora da UNESP, 1999. p. 137-191.

6 Cabem aqui as seguintes considerações de Douglas Kellner: "Assim, a leitura que Marcuse e Neumann faziam da filosofia antiga continha uma teoria da mudança social que era definida pela busca das condições que produziriam a mais alta realização do indivíduo. Esse projeto começa, eles afirmam, com os sofistas e continua através de Platão, Aristóteles e as escolas gregas e romanas posteriores via filosofia medieval até a filosofia moderna". Cf. KELLNER, Douglas. Tecnologia, guerra e fascismo: Marcuse nos anos 40. In: MARCUSE, Herbert. Tecnologia, guerra e fascismo. Tradução de Maria Cristina Vidal Borba; revisão de tradução de Isabel Maria Loureiro. São Paulo: Fundação Editora da UNESP, 1999. p. 38.

7 Essa perspectiva de leitura pode ser vista em Pensamento negativo: a lógica derrotada do protesto. Cf. MARCUSE, Herbert. O homem unidimensional: estudos da ideologia da sociedade industrial avançada. Trad. Robespierre de Oliveira, Deborah Christina Antunes, Rafael Cordeiro Silva. São Paulo: EDIPRO, 2015. p. $137-152$.

8 A respeito da problemática sobre a existência ou não de um corpus platônico, $C f$. SANTOS, J. G. Trindade. Para Ler Platão: A ontoepistemologia dos diálogos socráticos. Tomo I. São Paulo: Edições Loyola, $2008 \mathrm{a}$. p. 9-17.

\begin{tabular}{|l|l|l|l|l|}
\hline Qevista Dialectus & Ano 9 & n. 16 & Janeiro-Abril 2020 & p. 38-51 \\
\hline
\end{tabular}


objetivo de investigar os elementos presentes na constituição filosófica platônica que, segundo Marcuse, são imprescindíveis para uma prática histórica libertadora.

\section{A busca por uma dialética de alteração institucional em Platão}

Na tradição da Teoria Crítica da Escola de Frankfurt, Herbert Marcuse está entre os teóricos críticos sociais mais engajados na análise das novas configurações políticoeconômicas e culturais das sociedades capitalistas contemporâneas (KELLNER, 2015, p. 15). Em O homem unidimensional, sua análise está focada na contenção da mudança social (KELLNER, 2015, p. 26), sendo a integração da oposição ao status quo tecnologizado um fator-chave desse processo. Trata-se, aqui, da repressão de todas "as ideias, aspirações e valores que não podem ser definidos nos termos das operações e atitudes validadas pelas formas vigentes da racionalidade" ${ }^{9}$. Daí o conceito de racionalidade tecnológica desenvolvido por Marcuse traduzir, em outros termos, a lógica da dominação contida na racionalidade instrumental, técnica, científica - de seus companheiros do Instituto para a Pesquisa Social ${ }^{10}$.

Ao escrever Pensamento negativo: a lógica derrotada do protesto, Marcuse se propôs a identificar, nos estágios de desenvolvimento da civilização, o processo pelo qual a lógica se torna lógica da dominação. Partindo dessa proposta, o filósofo aborda os limites da lógica formal, simbólica e matemática, compreendendo que o problema dessas formas lógicas está na adaptabilidade de suas regras à lógica de dominação na sociedade tecnológica. Em linhas gerais, o que se busca é demonstrar que, no atual estágio da sociedade industrial avançada, o universo estabelecido do discurso está comprometido com um projeto tecnológico configurado para reproduzir a lógica da dominação. Segundo Marcuse,

Os métodos do procedimento tecnológico são muito diferentes nas lógicas antiga e moderna, mas a despeito de toda diferença está a construção de uma ordem de pensamento universalmente válida, neutra em relação ao conteúdo material. Muito antes do homem e da natureza tecnológica emergirem como objetos do controle e do

9 Cf. MAAR, W. L.. A educação pela revolução. In: Revista CULT, São Paulo, v. 127, p. 44-47, 01. ago. 2008. p. 47.

10 De acordo com Olgária Matos: "Os frankfurtianos desenvolveram uma explicação sobre o fenômeno do totalitarismo que é de ordem metafísica: é na constituição do conceito de Razão, é no exercício de uma determinada figura, ou modo da racionalidade, que esses filósofos alojam a origem do irracional. Em nome de uma racionalização crescente, os processos sociais são dominados pela ótica da racionalidade científica, característica da filosofia positivista. Nessa perspectiva, a realidade social, dinâmica, complexa, cambiante, é submetida a um método que se pretende universalizador e unitário, o método científico. O positivismo, prisioneiro de seus próprios métodos, impõe um procedimento não-social nas ciências sociais”. Cf. MATOS, Olgária C. F. A escola de Frankfurt: luzes e sombras do Iluminismo. São Paulo: Moderna, 1993. p. 7.

\begin{tabular}{|c|c|c|c|c|}
\hline Revita Didectus & Ano 9 & n. 16 & Janeiro - Abril 2020 & p. $38-51$ \\
\hline
\end{tabular}


cálculo racional, a mente tornou-se suscetível à generalização abstrata. Os termos que poderiam ser organizados em um sistema lógico coerente, livre de contradição ou com uma contradição manejável, foram separados daqueles que não o poderiam ser (MARCUSE, 2015, p. 148).

Diante desse quadro, Marcuse apresenta uma análise da lógica dialética, com o objetivo de evidenciar os elementos emancipatórios da Razão capazes de se contrapor à lógica da dominação na sociedade industrial avançada. Nesse sentido, o filósofo discorre sobre o conceito de pensamento negativo, resgatando justamente o conteúdo material do pensamento dialético. Para Marcuse, o "poder do pensar negativo é a força motriz do pensamento dialético, utilizado como instrumento para analisar o mundo dos fatos em termos de sua inadequação interna" (MARCUSE, 2014, p. 175). Portanto, o projeto marcuseano se engaja na tentativa de unir tanto teoria e prática quanto pensamento e ação, de modo que o poder do pensamento negativo, bem como "os elementos subversivos da razão", se materializem em práticas históricas libertadoras.

O pensamento não tem poder para realizar tal transformação a menos que ele transcenda a si mesmo em prática, e a dissociação da prática material, da qual a filosofia se origina, dá ao pensamento filosófico sua qualidade abstrata e ideológica. Em virtude dessa dissociação, o pensamento filosófico crítico é necessariamente transcendente e abstrato (MARCUSE, 2015, p. 145).

Na filosofia política de Marcuse, a teoria crítica deve se utilizar de categorias estruturadas pela lógica dialética para analisar o universo estabelecido do discurso. Segundo Douglas Kellner, o projeto de Marcuse "envolveu o questionamento dos conceitos de essência, felicidade, liberdade e, especialmente, a razão crítica, que ele acreditava ser a categoria central do pensamento filosófico e crítico" (KELLNER, 2015, p. 12). Daí o esforço de Marcuse em resgatar, na dialética platônica ${ }^{11}$, fundamentos para uma concepção de razão que seja antagônica ao processo de racionalização característico da sociedade industrial avançada. Isso porque Marcuse identifica, na racionalidade tecnológica, o continuum histórico da dominação (MARCUSE, 2015, p. 36). Vejamos como Marcuse compreende a concepção de razão na filosofia antiga:

11 Sobre a dialética, Leandro Konder escreve: "Depois dos gregos, a dialética foi chutada para escanteio, teve suas dimensões reduzidas às de uma lógica menor. Sintomaticamente, começou a recuperar suas forças no Renascimento. Foi com o alemão Hegel, entretanto, que se deu seu retorno glorioso à arena dos gladiadores" Cf. KONDER, Leandro. Em torno de Marx. São Paulo: Boitempo, 2010. p. 51.

\begin{tabular}{|c|c|c|c|c|}
\hline Q Rovista Oialectus & Ano 9 & n. 16 & Janeiro - Abril 2020 & p. $38-51$ \\
\hline
\end{tabular}


Na filosofia clássica grega, a Razão é a faculdade cognitiva para distinguir o que é verdadeiro do que é falso na medida em que a verdade (e falsidade) é essencialmente a condição do Ser, da realidade - e apenas nesse sentido é uma propriedade de proposições. O discurso verdadeiro, lógico, revela e expressa aquilo que realmente é - como distinto do que aparenta ser (real). E em virtude dessa equação entre Verdade e Ser (real), Verdadeiro é um valor, uma vez que Ser é melhor do que nãoSer. O último não é simplesmente Nada; ele é uma potencialidade e uma ameaça do Ser - destruição (MARCUSE, 2015, p. 138).

Desde o aparecimento do princípio de identidade na cultura grega, cuja fórmula encontra-se no fragmento 2 do Poema de Parmênides, no qual o eleata anuncia "os únicos caminhos de investigação que há para pensar: um que é, que não é para não ser, [...] o outro que não é, que tem de não ser" ${ }^{\text {"12, }}$ o indivíduo dispôs de um valioso critério para distinguir o que é essencialmente "verdadeiro" ou "falso" na realidade, ou seja, aquilo que é (ser, verdade) e aquilo que não é (não-ser, falso). Partindo daí, o pensamento marcuseano entende que a Razão é a faculdade cognitiva capaz de identificar os atributos do Ser. Nesse esquema lógico-filosófico grego, o "processo de identificação" constitui o ponto de partida através do qual o pensamento humano elabora um conhecimento válido sobre os objetos do mundo, pois através dele, o sujeito consegue distinguir o "mundo das aparências" (aquilo que não é) do "mundo real" (aquilo que é) ${ }^{13}$. Nessa dinâmica, o conflito entre homem e natureza é iminente, como bem explica Marcuse:

\begin{abstract}
A luta pela verdade é uma luta contra a destruição, pela "salvação" do Ser (um esforço que em si parece ser destrutivo se critica uma realidade estabelecida como "falsa": Sócrates contra a Cidade-Estado ateniense). Visto que a luta pela verdade "salva" a realidade da destruição, a verdade arrisca e compromete a existência humana. Esse é o projeto essencialmente humano. Se o homem aprendeu a ver e saber o que realmente é, ele agirá de acordo com a verdade. A epistemologia é ética em si mesma, e a ética é epistemologia (MARCUSE, 2015, p. 138).
\end{abstract}

Mais adiante, Marcuse ainda acrescenta que "essa concepção reflete a experiência de um mundo antagônico em si mesmo - um mundo afligido pela necessidade e pela

12 PARMÊNIDES. Da Natureza. Tradução de José Trindade Santos. São Paulo: Edições Loyola, 2002. B2. Segundo Gabriel Trindade, os dois caminhos de Parmênides podem ser condensados "nos três princípios lógicos que a tradição instituiu como tutelares do pensamento: 1. identidade $(A=A)$; 2. contradição $(A \neq \sim A)$; 3. terceiro excluído (AV A). Por outras palavras: 1. a afirmação é igual à afirmação, e a negação à negação; 2. a afirmação é diferente da negação; 3. entre a afirmação e a negação não há meio termo.” SANTOS, J. G. Trindade. Interpretação do Poema de Parmênides. In: PARMÊNIDES. Da Natureza. Tradução de José Trindade Santos. São Paulo: Edições Loyola, 2002. p. 67.

13 Sobre o processo de identificação postular a estabilidade e permanência das feições da natureza, Caio Prado Júnior escreve: “A identificação, ou, em outras palavras, aquela relativa uniformização e fixação da Natureza que constitui o processo ou ato de identificação, para o fim de reconhecimento do meio em que vive, e de reagir em consequência, é assim para o homem uma condição necessária de sua própria subsistência". $C f$. PRADO JÚNIOR, Caio. Introdução à dialética (notas introdutórias). 4. ed. São Paulo: Brasiliense, 1979. p. 17.

\begin{tabular}{|l|l|l|l|l|}
\hline Qevista Dialectus & Ano 9 & n. 16 & Janeiro - Abril 2020 & p. $38-51$ \\
\hline
\end{tabular}


negatividade" (MARCUSE, 2015, p. 138). Trata-se, aqui, do conteúdo político e transformador contido nos grandes conceitos da filosofia clássica grega, cuja tarefa é identificar os elementos falsos que permeiam a realidade estabelecida ${ }^{14}$. Nessa ótica, Marcuse busca identificar, na filosofia de Platão, elementos comprometidos com uma dialética de alteração institucional $^{15}$, de modo que "as essências platônicas simbolizam a possibilidade de harmonização entre a realidade e uma ordem social" (MERQUIOR, 2017, p. 35). Numa palavra, Marcuse articula elementos platônicos que possam ser integrados em seu projeto por uma mudança social radical.

\section{Elementos platônicos para uma teoria crítica da sociedade}

Segundo a filosofia platônica, os verdadeiros filósofos são "amadores do espetáculo da verdade" (Rep., 475e) e "amigos da sabedoria” (Rep., 480a), uma vez que buscam o conhecimento daquilo que é e "se dedicam ao Ser em si" (Rep., 480a) ${ }^{16}$. O conhecimento daquilo que é, no entanto, não pode ser alcançado através dos sentidos, posto que os objetos de natureza inteligível só sejam apreensíveis pela razão.

Essa nova concepção de saber é apresentada por Platão, de outra maneira, em sua metáfora da "segunda navegação", no Fédon, onde o filósofo ateniense postula "duas espécies de coisas: umas visíveis e outras invisíveis [...] sendo que as invisíveis são sempre idênticas a si mesmas, e as visíveis o contrário disso" (Féd., 79a). Nessa conjectura, admite-se a existência de dois planos do ser: 1) um fenomênico e visível, de perspectiva naturalistamecanicista; e 2) outro invisível e metafenomênico, de perspectiva metafísico-gnosiológica,

14 Nas palavras de Douglas Kellner: "A teoria de Marcuse pressupõe a existência de um sujeito humano com liberdade, criatividade e autodeterminação que está em oposição a um mundo-objeto, percebido como substância, que contém possibilidades a serem realizadas e qualidades secundárias como valores, feições estéticas e aspirações que podem ser cultivadas para melhorar a vida humana”. $C f$. KELLNER, Douglas. Introdução à $2^{a}$ edição. In: MARCUSE, Herbert. $O$ homem unidimensional: estudos da ideologia da sociedade industrial avançada. Tradução de Robespierre de Oliveira, Deborah Christina Antunes, Rafael Cordeiro Silva. São Paulo: Edipro, 2015. p. 21.

15 Para compreender o desenvolvimento deste raciocínio, destacamos a passagem 473 b da República, na qual Sócrates afirma: "Depois disto então, ao que parece, temos de procurar indagar e demonstrar que espécie de defeito há actualmente nas cidades, devido ao qual não são assim organizadas, e qual a menor mudança possível pela qual a cidade passaria ao nosso sistema de administração - uma só alteração, de preferência; se não, duas; se não, as menos possível em número e as menores em alcance”. Cf. PLATÃO. A República. Tradução e notas de Maria Helena Rocha Pereira. 14. ed. Lisboa: Fundação Calouste Gulbenkian, 2014. $473 b$.

16 No passo 485a-b da República, Sócrates ainda afirma que os filósofos, por natureza, “estão sempre apaixonados pelo saber que possa revelar-lhes algo daquela essência que existe sempre, e que não se desvirtua por ação da geração e da corrupção" e, além disso, "estão apaixonados pela essência na sua totalidade”. Mais adiante, em 501d, continua: “os filósofos não são uns apaixonados do Ser e da verdade?”.

\begin{tabular}{|c|c|c|c|c|}
\hline Revita Didectus & Ano 9 & n. 16 & Janeiro - Abril 2020 & p. $38-51$ \\
\hline
\end{tabular}


puramente inteligível ${ }^{17}$ e epistemologicamente anterior ao primeiro plano. Consequentemente, admite-se também a existência de dois modos de captação da realidade: 1) um através dos sentidos, pelo qual o indivíduo permanece prisioneiro das aparências e produz opinião; e 2) outro através do pensamento, pelo qual o indivíduo liberta-se dos grilhões da aparência e inicia sua ascensão ao exterior da caverna, produzindo saber. O primeiro é próprio dos amadores de espetáculos e filodóxos, o segundo, dos filósofos ${ }^{18}$.

Assim, enquanto a "primeira navegação" direciona-se ao plano visível, buscando causas físicas para toda a realidade sensível, a "segunda negação" abandona o método de investigação por meio dos sentidos e eleva-se ao pensamento, "para nele contemplar a verdadeira natureza das coisas" (Féd., 99e), apresentando uma nova proposta metodológica para a aquisição do saber, na qual as formas auto-subsistentes são apontadas como a causa de toda a realidade sensível - que só é enquanto participa do inteligível. Com essa revolucionária concepção de saber, Platão também desenvolve um novo modo de compreender conceitos como o Bem, antes negado pela observação das realidades sensíveis ${ }^{19}$.

Diante dessa breve introdução ao pensamento de Platão, podemos perguntar pelos elementos constituintes da filosofia platônica que podem ser articulados numa teoria crítica da sociedade. Voltemos, portanto, à leitura marcuseana de Platão. Na concepção platônica assim interpreta o filósofo berlinense -, o sujeito que abrange a condição ontológica do verdadeiro e do falso é aquele que domina a pura contemplação (theoria), ou seja, aquele que domina uma prática guiada pela teoria (MARCUSE, 2015, p. 141). Delinearemos, abaixo, algumas considerações que sustentam este ponto de vista.

No Mênon, ao confrontar um escravo que não possuía instruções prévias sobre geometria com o problema da construção de um quadrado de área dupla de um quadrado dado, Sócrates demonstra que um interrogatório corretamente conduzido é capaz de dirigir qualquer indivíduo ignorante ao conhecimento ou à "reminiscência" ${ }^{20}$. Isso é possível

17 Cf. REALE, Giovanni. História da filosofia: Antiguidade e idade média. 8. ed. São Paulo: PAULUS, 2003. p. 134-136.

18 Para Platão, ao alcançar o mundo exterior e apreender a verdadeira realidade, é necessário que o filósofo retorne à caverna e conduza os prisioneiros em direção ao caminho que os leva à saída, ainda que este retorno possa custar-lhe a vida. Nesse sentido, podemos compreender que a proposta educacional de Platão tem por objetivo proporcionar uma mudança qualitativa na vida dos homens, elevando-os de um nível inferior de vida para um nível superior e autenticamente humano. Para uma leitura da Alegoria da Caverna, vide: Rep., 514a518a.

19 Cf. SANTOS, J. G. Trindade. Para Ler Platão: O problema do saber nos diálogos sobre a teoria das formas. Tomo II. São Paulo: Edições Loyola, 2008b. p. 67-70

20 "Se, em verdade, segundo penso, antes de nascer já tínhamos tal conhecimento e o perdemos ao nascimento, e depois, aplicando nossos sentidos a esses objetos, voltamos a adquirir o conhecimento que já possuíramos num tempo anterior: o que denominamos aprender não será a recuperação de um conhecimento muito nosso?

\begin{tabular}{|c|c|c|c|c|}
\hline Rovita Q Didectus & Ano 9 & ก. 16 & Janeiro - Abril 2020 & p. $38-51$ \\
\hline
\end{tabular}


porque, segundo Platão, o conhecimento é formativo da alma humana, uma vez que esta contemplou "alguns dos verdadeiros seres" (Fedr., 248c) anteriormente, enquanto habitava em um "lugar supraceleste" (Fedr., 247c). Assim, através do exercício dialógico todos os homens são capazes de ter acesso ao conhecimento que já carregam consigo. Nessa conjectura, a verdade encontra-se em todos os homens, na medida em que todos desfrutam da possibilidade de construir um caminho até as formas inteligíveis. O que distingue cada homem do outro, portanto, é a medida de sua ignorância, isto é, do seu esquecimento. Tal esquecimento, contudo, pode ser remediado pela educação filosófica. Dessa forma, a verdade que os filósofos conhecem e expõem está potencialmente acessível a todos, como observa Marcuse:

\begin{abstract}
Guiado pelo filósofo, o escravo no Mênon de Platão é capaz de alcançar a verdade de um axioma geométrico, i.e., a verdade para além da mudança e da corrupção. Mas uma vez que a verdade é um estado do Ser assim como do pensamento, e uma vez que o último é a expressão e a manifestação do primeiro, o acesso à verdade permanece mera potencialidade enquanto ele não estiver vivendo na e com a verdade. E essa forma de existência está fechada para o escravo - e a qualquer um que tem que passar sua vida satisfazendo as necessidades da vida. Consequentemente, se os homens não mais tivessem que passar suas vidas no reino da necessidade, a verdade e uma existência verdadeiramente humana seriam universais de modo estrito e real (MARCUSE, 2015, p. 141-142).
\end{abstract}

Marcuse observa que a filosofia platônica tem por objetivo conduzir os indivíduos à contemplação das verdadeiras realidades, as forma inteligíveis ${ }^{21}$, paradigmas ou pontos de referência através dos quais todos os homens devem guiar seus pensamentos e ações ${ }^{22}$, distinguindo aquilo que é das "aparências de verdade" que permeiam o reino da necessidade ${ }^{23}$. Ora, pensar e agir em função do reino da necessidade subordina o homem a um modo de vida contingente e até contrário a sua natureza essencial, portanto, de modo como não é. Daí a relação antagônica entre 1) o modo no qual homens e coisas não são e 2) o modo

E não estaremos empregando a expressão correta, se dermos a esse processo o nome de reminiscência?" (Féd., 75e).

21 Segundo Giovanni Reale: "Platão denominou essas causas de natureza não-física, essas realidades inteligíveis, principalmente recorrendo aos termos Ideia e Eidos, que significam 'forma' [...] As Ideias, em suma, não são simples pensamentos, mas aquilo que o pensamento pensa quando liberto do sensível: constituem o 'verdadeiro ser', o 'ser por excelência' [...] As Ideias platônicas são as essências das coisas, ou seja, aquilo que faz com que cada coisa seja aquilo que é [...]” (REALE, 2003, p. 137).

22 "Parece-te que há alguma diferença entre os cegos e aqueles que estão realmente privados do conhecimento de todo o ser, e que não têm na alma nenhum paradigma claro, nem são capazes de olhar, como pintores, para a verdade absoluta, tomando-a sempre como ponto de referência, e contemplando-a com o maior rigor possível, para só então promulgar leis cá na terra sobre o belo, o justo, o bom, se for caso disso, e preservar as que existem, mantendo-as a salvo?” (Rep., 484c-d).

23 Partindo da admissão da realidade das Formas, as causas finais passam a ser investigadas pela dialética, ou seja, pela "investigação por meio dos argumentos" (SANTOS, 2008b, p. 70).

\begin{tabular}{|c|c|c|c|c|}
\hline Qovista Dialectus & Ano 9 & n. 16 & Janeiro - Abril 2020 & p. $38-51$ \\
\hline
\end{tabular}


no qual homens e coisas são "por si mesmos" e "como si mesmos" (MARCUSE, 2015, p. 139). Na citação abaixo, podemos observar que Marcuse amplia esse ponto de vista:

\begin{abstract}
A experiência do mundo cindido encontra sua lógica na dialética platônica. Aqui, os termos "Ser", "Não-ser", "Movimento", "O Uno e o Múltiplo", "Identidade" e "Contradição" são metodicamente mantidos abertos, ambíguos, sem definição completa. Eles têm um horizonte aberto, um universo inteiro de significado que é estruturado gradualmente no próprio processo de comunicação, mas que nunca é terminado. As proposições são submetidas, desenvolvidas e testadas em um diálogo, no qual o parceiro é levado a questionar o universo normalmente inquestionado da experiência e da fala, e a entrar em uma nova dimensão do discurso diferentemente, aqui ele é livre e o discurso é voltado para sua liberdade. Ele deve ir além daquilo que lhe é dado - como aquele que fala, em sua proposição, vai além do conjunto inicial de termos (MARCUSE, 2015, p. 143).
\end{abstract}

É nesse sentido que, na dialética platônica, o predicativo é implica um dever ser, pois, no âmbito da realidade dada, a forma (verdade) concebida dialogicamente é mera essência e potencialidade, sendo necessário, portanto, sua transição em ato ${ }^{24}$. Ora, se o sujeito humano apreende uma verdade que não esteja realizada na práxis social, torna-se inevitável que haja um conflito entre pensamento e realidade. Essa dinâmica é descrita por Marcuse nos seguintes termos:

[...] As leis do pensamento são leis da realidade, ou melhor, se tornam as leis da realidade se o pensamento entende a verdade da experiência imediata como a aparência de outra verdade, que é aquela das formas verdadeiras da realidade - das Ideias. Assim existe contradição ao invés de correspondência entre o pensamento dialético e a realidade dada; o juízo verdadeiro julga essa realidade não em seus próprios termos, mas em termos que idealizam sua subversão. E nessa subversão, a realidade se transforma em sua própria verdade (MARCUSE, 2015, p. 143-144).

Nessa perspectiva, o "mundo das experiências imediatas - o mundo no qual nos encontramos vivendo - precisa ser compreendido, transformado, até subvertido para se tornar o que ele realmente é" (MARCUSE, 2015, p. 137). Que tipo de pensamento bidimensional lida com a realidade dessa forma? Para Marcuse, a resposta é evidente: o pensamento dialético. Em Razão e revolução (1941), Marcuse expõe uma leitura hegeliana de Platão que resgata o processo pelo qual o pensamento apreende o objeto da forma como ele é (em suas qualidades essenciais), e, com isso, se põe numa relação antagônica com a realidade contingente. Segundo essa leitura,

24 Sobre essa noção, Marcuse escreve: "Para o Platão dos últimos Diálogos e para Aristóteles, as formas do Ser são formas de movimento - transição de potencialidade para atualidade, realização. O Ser finito é realização incompleta, sujeito a mudança. Sua geração é corrupção; é permeada por negatividade. Assim, ele não é a realidade verdadeira - a Verdade" (MARCUSE, 2015, p. 140).

\begin{tabular}{|c|c|c|c|c|}
\hline Revita Alatectus & Ano 9 & n. 16 & Janeiro - Abril 2020 & p. $38-51$ \\
\hline
\end{tabular}


O homem tem uma ideia do belo, do bem, etc., no seu conceito de beleza, bondade, etc. O conceito compreende o que é verdadeiramente o belo e o bem, e Sócrates exorta o sujeito pensante a descobrir esta verdade e a sustentá-la contra qualquer autoridade externa. Sócrates, portanto, põe a verdade à parte, como um universal, e atribui ao pensamento autônomo do indivíduo o conhecimento deste universal. Assim fazendo, ele "aponta o indivíduo como sujeito de todas as decisões finais, contra a pátria e a moral vigente". Os princípios de Sócrates ensinam uma "oposição revolucionária ao Estado ateniense". Sócrates foi condenado à morte. Este ato se justificava na medida em que os atenienses estavam condenando seu "adversário absoluto". Por outro lado, a sentença de morte continha um elemento "profundamente trágico": através dela os atenienses estavam também condenando sua sociedade e seu Estado (MARCUSE, 2004, p. 210-211).

Diante da análise hegeliana, notamos uma abordagem revolucionária da filosofia de Platão. A partir dela, identificamos em Sócrates o sujeito que dispõe das categorias necessárias para compreender a realidade. Partindo desse ponto, o movimento do pensamento socrático adquire um conteúdo político, pois a busca pela verdadeira definição de conceitos por exemplo, Liberdade, Justiça, Felicidade e Bem - almeja por uma nova polis. Ao definir seus conceitos em termos de potencialidades que são de uma ordem de pensamento essencialmente negativo ao establishment ${ }^{25}$, Sócrates inevitavelmente se contrapôs ao Estado ateniense. Como resultado, Sócrates não apenas foi acusado de corromper a juventude, mas também condenado à morte por impiedade (REALE, 2003, p. 85). O desenrolar desta história remete a concepção hegeliana de "astúcia da razão":

[...] Hegel exalta o sacrifício da felicidade individual e geral [...] Ele chamou este sacrifício a "astúcia da razão". Os indivíduos levam uma vida infeliz, trabalham arduamente, e morrem; entretanto, embora jamais realizem seus desígnios, seu sofrimento e seu fracasso são os meios mesmos de sustentação da verdade e da liberdade. Um homem jamais colhe os frutos do seu trabalho; eles sempre ficam para as gerações futuras [...] Os indivíduos morrem e fracassam; a ideia triunfa e é eterna (MARCUSE, 2004, p. 202-203).

A partir dessa definição, podemos sustentar que a "astúcia da razão" se apresenta como o "elemento profundamente trágico" da sentença de morte proferida pelo Estado ateniense. Sócrates morreu; porém, suas ideias permaneceram imunes ao efeito mortífero da cicuta. Nessa conjuntura, o sacrifício de Sócrates foi ocasionado por sua busca pela verdade. Se assumirmos o pressuposto de que viver em um mundo de saber depende da escolha do

25 No entender de Marcuse: "A verdade concebida pelo pensamento é a Ideia. Como tal, em termos da realidade dada, é "mera” Ideia, "mera" essência - potencialidade” (MARCUSE, 2015, p. 144).

\begin{tabular}{|c|c|c|c|c|}
\hline Rovista Dialectus & Ano 9 & n. 16 & Janeiro - Abril 2020 & p. $38-51$ \\
\hline
\end{tabular}


sujeito livre, podemos afirmar que Sócrates escolheu viver como um homem livre ${ }^{26}$. Em termos marcuseanos, Sócrates foi condenado por ser o agente histórico cuja identidade se constitui dentro da sua prática histórica. Vejamos como Marcuse compreende essa concepção dialética da realidade:

\begin{abstract}
Quando o conteúdo histórico entra no conceito dialético e determina metodologicamente seu desenvolvimento e função, o pensamento dialético alcança a concretude que liga a estrutura do pensamento à da realidade. A verdade lógica se torna a verdade histórica. A tensão ontológica entre "essência" e "aparência", entre "ser" e "dever", se torna uma tensão histórica e a "negatividade interna" do mundo objetivo é entendida como a obra do sujeito histórico - o homem em sua luta com a natureza e a sociedade. A Razão se torna Razão histórica. Ela contradiz a ordem estabelecida dos homens e das coisas em nome das forças sociais existentes que revelam o caráter irracional dessa ordem - porque "racional" é um modo de pensamento e ação que é orientado para a redução da ignorância, da destruição, da brutalidade e da opressão (MARCUSE, 2015, p. 151).
\end{abstract}

Nessa perspectiva, a dialética se desencadeia numa dinâmica que envolve homem e natureza, sujeito e objeto, e, segundo o exposto acima, Sócrates e o Estado ateniense. Para Marcuse, as condições materiais de existência - o "mundo-objeto" - são resultados de ações efetivadas pelo sujeito humano, tendo em vista que a racionalização da verdade nas palavras e ações do homem possibilita a sua intervenção na realidade social (MARCUSE, 2015, p. 145). Compreendendo que o pensamento dialético abstrai a racionalidade de um universo bidimensional do discurso (MARCUSE, 2015, p. 142), a teoria crítica busca confrontar a má facticidade da realidade social com as suas melhores possibilidades ${ }^{27}$. Conforme explica Douglas Kellner,

Tal posição crítica requer desenvolver o que Marcuse denomina "pensamento negativo", que "nega" as formas existentes de pensamento e realidade da perspectiva de suas possibilidades superiores. Essa prática pressupõe a habilidade de fazer a distinção entre a existência e essência, fato e potencialidade, aparência e realidade. A mera existência poderia ser negada em favor da realização de potencialidades superiores, enquanto normas descobertas pela razão seriam usadas para criticar e ultrapassar formas inferiores de pensamento e organização social. Assim, compreender as possibilidades de liberdade e felicidade tornaria possível a negação de condições que impedem o pleno desenvolvimento e realização dos indivíduos (KELLNER, 2015, p. 12).

26 Para o filósofo da contestação, o "pensamento racional livre, mais cedo ou mais tarde, terá de entrar em luta com as racionalizações de vida existente". Cf. MARCUSE, Herbert. Razão e revolução: Hegel e o advento da teoria social. Tradução de Marília Barroso. São Paulo: Paz e Terra, 2004. p. 207.

27 MARCUSE, Herbert. Cultura e Sociedade Volume I. Tradução de Wolfgang Leo Maar, Isabel Maria Loureiro, Robespierre de Oliveira. São Paulo: Editora Paz e Terra S.A., 1997. p. 145.

\begin{tabular}{|l|l|l|l|l|}
\hline Q Povista Dialectus & Ano 9 & n. 16 & Janeiro-Abril 2020 & p. $38-51$ \\
\hline
\end{tabular}


Posto isso, segue-se a pergunta: como o pensamento articula, p. ex., o conhecimento das possibilidades de práxis da liberdade e felicidade na realidade social? Através do que desenvolvemos até agora, verificamos que o conhecimento é mediado pela faculdade cognitiva da Razão, que, no esquema lógico-filosófico clássico, se articula por meio do processo de identificação das qualidades essenciais que formulam as concepções de liberdade e felicidade, isto é, do ser (verdade) que estas concepções exprimem. Sendo assim, como uma teoria pode se utilizar da verdade contida nos conceitos para articular uma análise crítica da realidade, de modo a promover uma práxis histórica libertadora? De acordo com o que vimos, a teoria crítica da sociedade tem a tarefa de se engajar na luta contra os elementos mistificadores do sistema político estabelecido, ou, em termos platônicos, na luta contra o "mundo das aparências". Portanto, o sujeito humano deve, por meio das normas estabelecidas pela razão, direcionar seu pensamento e ação contra a falsidade contida no universo estabelecido do discurso e da ação. Daí a atividade filosófica assumir, em Marcuse, um aspecto subversivo, tendo em vista que a negação é a categoria central da dialética ${ }^{28}$.

A partir do que foi apresentado, defendemos que é tarefa do filósofo buscar, na história da filosofia, uma chave de leitura voltada para uma mudança social comprometida com a emancipação dos indivíduos, pois a história humana ainda é a história da dominação e a lógica do pensamento continua sendo a lógica da dominação (MARCUSE, 2015, p. 149). Em seu projeto, Marcuse buscou, nos clássicos da cultura ocidental, elementos que contribuíssem para uma transformação social que possibilitasse a mais alta realização dos indivíduos. Marcuse decodificou a filosofia platônica sob essa perspectiva. Mas não só isso: ele também articulou os elementos platônicos em sua teoria crítica da sociedade.

Sabemos da influência de Hegel e Marx no desenvolvimento da dialética que tanto influenciou o pensamento de Marcuse. No entanto, podemos perguntar: sem a segunda navegação de Platão, seríamos capazes de conjecturar novos modos de pensamento e comportamento, bem como uma nova ordem social? Em outras palavras, sem a descoberta da dimensão metafísica do pensamento, seríamos capazes de pensar sobre a Paz, Solidariedade e Justiça, de modo a promover um mundo verdadeiramente humano? Sendo mais nevrálgico: se os grandes conceitos filosóficos da história fossem incapazes de proporcionar uma prática histórica libertadora, Sócrates teria sido condenado a beber a cicuta?

28 MARCUSE, Herbert. Uma nota sobre a dialética. Tradução de Alberto Dias Gadanha. In: GADANHA, Alberto Dias. Razão e revolução: de Herbert Marcuse, por uma dialética de alteração institucional. 2014. 171 f. Tese (Doutorado em Filosofia) - Programa de Pós-Graduação em Filosofia, Universidade Federal da Paraíba, João Pessoa, 2014. p. 162.

\begin{tabular}{|l|c|c|c|c|}
\hline Qovista Dialectus & Ano 9 & n. 16 & Janeiro - Abril 2020 & p. $38-51$ \\
\hline
\end{tabular}




\section{Referências}

KELLNER, Douglas. Introdução à $\mathbf{2}^{\mathbf{a}}$ edição. In: MARCUSE, Herbert. O homem unidimensional: estudos da ideologia da sociedade industrial avançada. Tradução de Robespierre de Oliveira, Deborah Christina Antunes, Rafael Cordeiro Silva. São Paulo: Edipro, 2015.

Tecnologia, guerra e fascismo: Marcuse nos anos 40. In: MARCUSE, Herbert. Tecnologia, guerra e fascismo. Tradução de Maria Cristina Vidal Borba. São Paulo: Fundação Editora da UNESP, 1999.

KONDER, Leandro. Em torno de Marx. São Paulo: Boitempo, 2010.

MAAR, W. L. A educação pela revolução. In: Revista CULT, São Paulo, v. 127, p. 44-47, 01. ago. 2008.

MARCUSE, Herbert. Cultura e Sociedade Volume I. Tradução de Wolfgang Leo Maar, Isabel Maria Loureiro, Robespierre de Oliveira. São Paulo: Editora Paz e Terra S.A., 1997.

O homem unidimensional: estudos da ideologia da sociedade industrial avançada. Tradução de Robespierre de Oliveira, Deborah Christina Antunes, Rafael Cordeiro Silva. São Paulo: Edipro, 2015.

Razão e revolução: Hegel e o advento da teoria social. Tradução de Marília Barroso. São Paulo: Paz e Terra, 2004.

Tecnologia, guerra e fascismo. Tradução de Maria Cristina Vidal Borba; revisão de tradução de Isabel Maria Loureiro. São Paulo: Fundação Editora da UNESP, 1999.

. Uma nota sobre a dialética. Tradução de Alberto Dias Gadanha. In: GADANHA, Alberto Dias. Razão e revolução: de Herbert Marcuse, por uma dialética de alteração institucional. 2014. 171 f. Tese (Doutorado em Filosofia) - Programa de Pós-Graduação em Filosofia, Universidade Federal da Paraíba, João Pessoa, 2014.

MATOS, Olgária C. F. A escola de Frankfurt: luzes e sombras do Iluminismo. São Paulo: Moderna, 1993.

MERQUIOR, José Guilherme. Arte e sociedade em Marcuse, Adorno e Benjamin: ensaio crítico sobre a escola neo-hegeliana de Frankfurt. São Paulo: É Realizações, 2017.

PARMÊNIDES. Da Natureza. Tradução de José Trindade Santos. São Paulo: Edições Loyola, 2002.

\begin{tabular}{|l|l|l|l|l|}
\hline Q Povista Dialectus & Ano 9 & n. 16 & Janeiro - Abril 2020 & p. $38-51$ \\
\hline
\end{tabular}


PLATÃ̃. A República. 14. ed. Tradução de Maria Helena Rocha Pereira. Lisboa: Fundação Calouste Gulbenkian, 2014.

. Fédon. Tradução de Carlos Alberto Nunes. Belém: Ed.ufpa, 2011.

Fedro. Tradução de Maria Cecília Gomes dos Reis. São Paulo: Penguin Classics Companhia das Letras, 2016.

. Mênon. Tradução de Maura Iglésias. São Paulo: Edições Loyola, 2001.

PRADO JÚNIOR, Caio. Introdução à lógica dialética (notas introdutórias). 4. ed. São Paulo: Brasiliense, 1979.

REALE, Giovanni. História da filosofia: Antiguidade e idade média. 8. ed. São Paulo: Paulus, 2003.

SANTOS, J. G. Trindade. Interpretação do Poema de Parmênides. In: PARMÊNIDES. Da Natureza. Tradução de José Trindade Santos. São Paulo: Edições Loyola, 2002.

Para Ler Platão: a ontoepistemologia dos diálogos socráticos. Tomo I. São Paulo: Edições Loyola, 2008a.

Para Ler Platão: o problema do saber nos diálogos sobre a teoria das formas. Tomo II. São Paulo: Edições Loyola, 2008 b.

\begin{tabular}{|l|l|l|l|l|}
\hline Q Rovista Dialectus & Ano 9 & n. 16 & Janeiro-Abril 2020 & p. $38-51$ \\
\hline
\end{tabular}

